05

\title{
Откольная прочность и динамический предел текучести гафния
}

\author{
() А.М. Молодец ${ }^{1}$, А.С. Савиных ${ }^{1,2}$, А.А. Голышев ${ }^{1}$, Г.В. Гаркушин ${ }^{1,2}$ \\ ${ }^{1}$ Институт проблем химической фризики РАН, Черноголовка, Московская обл., Россия \\ ${ }^{2}$ Национальный исследовательский Томский государственный университет, Томск, Россия \\ E-mail: molodets@icp.ac.ru
}

Поступило в Редакцию 10 октября 2018 г.

\begin{abstract}
Откольная прочность и динамический предел текучести поликристаллического гафния измерены в серии плосковолновых ударных экспериментов с использованием методики плоских составных мишеней образец-прозрачное окно. Материалом прозрачного окна служили полиметилметакрилат и фтористый литий, которые располагались на тыльной стороне образца гафния. По фронтальной поверхности образца наносился удар медным ударником. Во всех экспериментах регистрировалась скорость тыльной поверхности образца, который сохранялся для последующего металлографического анализа. Полученные результаты использовались также для анализа точности измерения откольной прочности и особенностей высокоскоростной деформации гафния.
\end{abstract}

DOI: 10.21883/PJTF.2019.02.47219.17555

Переходные металлы IV группы (Ti, Zr, Hf) являются функциональными и конструкционными материалами таких отраслей, как атомная промышленность и космическая техника. Поэтому их физико-механические свойства, в том числе при ударно-волновых нагрузках, важны для ряда фундаментальных и прикладных задач металлофизики этих элементов. Исследованию прочностных свойств титана и циркония в условиях ударно-волнового нагружения посвящено большое число публикаций (см. работы [1,2] и ссылки в них). Однако подобная информация для гафния практически отсутствует в доступной литературе. При этом, как и в случае Ti, $\mathrm{Zr}$, интерес к изучению механических свойств гафния диктуется возрастающими требованиями к безопасности и надежности эксплуатации органов регулирования реакторов атомных станций, в том числе в экстремальных условиях высоких динамических давлений и темпераутр, которые возникают при авариях или в импульсных ядерных энегетичесикх установках в течение коротких, микросекундных времен. В связи с этим цель настоящей работы состоит в определении откольной прочности и динамического предела текучести гафния в области давлений ударного сжатия до $\sim 7 \mathrm{GPa}$.

Исследовался гафний марки ГФИ-1 с массовой концентрацией примесей $0.9 \% \mathrm{Zr}, 0.034 \% \mathrm{Fe}, 0.022 \% \mathrm{O}$, $0.02 \% \mathrm{C}, 0.016 \% \mathrm{Si}, 0.008 \%$ N. Образцы гафния представляли собой плоскопараллельные пластины. Большие плоские поверхности образцов шлифовались. Измеренная плотность образцов составила $\rho_{0}=13.280(5) \mathrm{g} / \mathrm{cm}^{3}$. Измеренная продольная скорость звука при нулевом давлении была равна $C_{l}=3.765(5) \mathrm{km} / \mathrm{s}$. Для объемной скорости звука $C_{0}$ использовалось значение $C_{0}=\left(K_{0} / \rho_{0}\right)^{1 / 2}=2.86 \mathrm{~km} / \mathrm{s}$, где $K_{0}=108.78 \mathrm{GPa}-$ справочное [3] значение адиабатического модуля объемного сжатия гафния при нормальных условиях. Используемые образцы имели примерно равноосную микроструктуру с размером зерна $50 \mu \mathrm{m}$ (рис. $1, a)$.
Прочностные свойства гафния изучались в трех сериях ударно-волновых экспериментов. Общая схема эксперимента показана на рис. 2. Ударно-волновое нагружение образцов осуществлялось пластинчатым ударником 1 , разогнанным до скорости $W_{0}$ в пневматической пушке. В эксперименте медная пластина-ударник 1 толщиной $\sim 2 \mathrm{~mm}$ и диаметром $48 \mathrm{~mm}$ соударялась с фронтальной поверхностью пластинчатого образца 2 толщиной $4 \mathrm{~mm}$, генерируя в нем ударную волну амплитудой $\sim 7 \mathrm{GPa}$.

Перед экспериментом давление воздуха в стволе пушки и в пространстве, окружающем образец, понижалось до $2 \mathrm{kPa}$. Тыльная поверхность образца контактировала с прозрачным окном 3, изготовленным из материала с малой (по сравнению с гафнием) динамической жесткостью. В первой серии материалом окна служил разреженный воздух, во второй и третьей сериях материалами окон толщиной $\sim 5$ и $\sim 8 \mathrm{~mm}$ служили полиметилметакрилат (РММА) и фтористый литий соответственно.
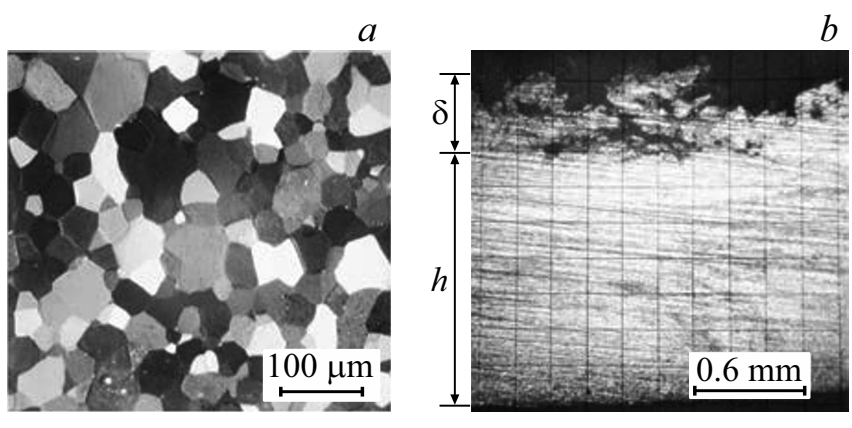

Рис. 1. Оптические микрофотографии сечений образцов гафния. $a-$ исходный образец, светлые и темные зерна представляют собой зерна гафния, различно ориентированные относительно плоскости шлифа, $b-$ шлиф поперечного сечения сохраненной откольной пластины образца гафния в эксперименте с воздушным окном. $h$ - толщина откольной пластины, $\delta-$ зона откольной поврежденности; направление удара для части $b-$ сверху вниз. 


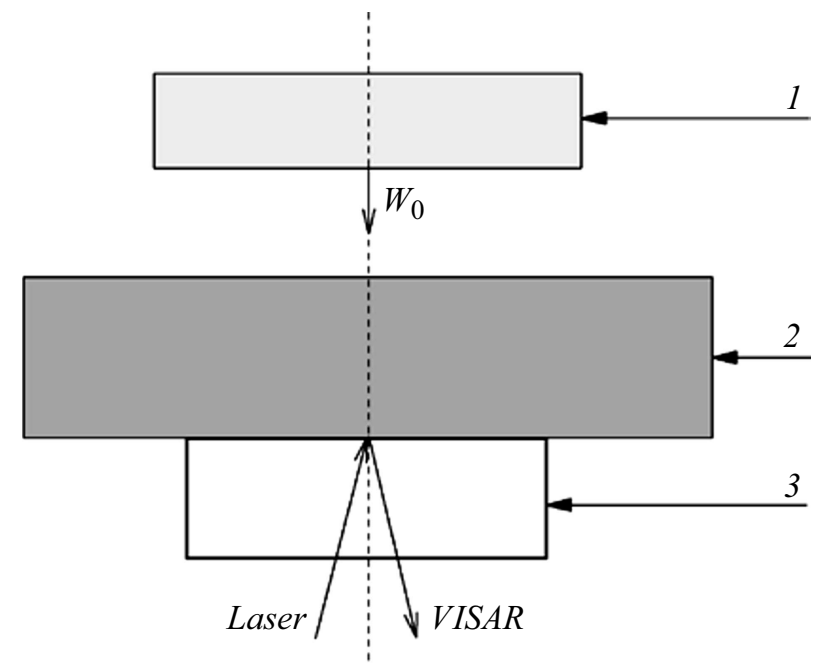

Рис. 2. Схема нагружения образцов и измерения скорости поверхности образца, контактирующей с окном. 1 - медный ударник толщиной $H_{\mathrm{Cu}}$, летящий со скоростью $W_{0}, 2-$ образец гафния толщиной $H_{0}, 3$ - прозрачное окно. Наклонными стрелками обозначен зондирующий световой луч лазера.

Таблица 1. Параметры ударников и образцов гафния в экспериментах с различными окнами

\begin{tabular}{c|c|c|c}
\hline $\begin{array}{c}\text { Материал } \\
\text { окна }\end{array}$ & $\begin{array}{c}W_{0}, \\
\mathrm{~m} / \mathrm{s}\end{array}$ & $\begin{array}{c}H_{\mathrm{Cu}}, \\
\mathrm{mm}\end{array}$ & $\begin{array}{c}H_{0}, \\
\mathrm{~mm}\end{array}$ \\
\hline Воздух & $361(10)$ & $1.995(5)$ & $3.798(5)$ \\
PMMA & $371(10)$ & $1.982(5)$ & $3.792(5)$ \\
$\mathrm{LiF}$ & $347(10)$ & $1.975(5)$ & $3.795(5)$
\end{tabular}

Непосредственно перед ударно-волновым нагружением образцы имели комнатную температуру.

Скорость ударника $\mathrm{W}_{0}$ измерялась электроконтактными датчиками с точностью $3 \%$. Зависимость скорости тыльной поверхности образца $U$ от времени $t$ (профиль $U(t))$ регистрировалась с помощью лазерного интерферометра VISAR [4]. Используемый интерферометрический комплекс позволял регистрировать профили $U(t)$ с точностью $2 \%$ с временнб́м разрешением около $1 \mathrm{~ns}$. Отношение толщины образца к его диаметру составляло приблизительно $1: 7$, что обеспечивало одноосное напряженное состояние образца в течение времени плоского ударно-волнового нагружения.

Экспериментальные профили скорости $U(t)$ тыльной поверхности образца показаны на рис. 3. В табл. 1 приведены скорость $W_{0}$ и толщина $H_{\mathrm{Cu}}$ медного ударника, а также исходная толщина образца $H_{0}$ гафния для каждой осциллограммы. Во всех экспериментах происходило откольное разрушение образцов гафния. В каждой серии производилось сохранение образцов. На рис. $1, b$ показан шлиф сохраненного образца для эксперимента с воздушным окном. Для всех экспериментов наблюдалось обра- зование откольной пластины толщиной $h=1.40(2) \mathrm{mm}$ и протяженной зоны разрушения $\delta \sim 0.35 \mathrm{~mm}$.

Значение $U_{\mathrm{HEL}}$ на профилях $U(t)$ с воздушным окном использовалось для расчета динамического предела упругости $\sigma_{\mathrm{HEL}}$

$$
\sigma_{\mathrm{HEL}}=0.5 U_{\mathrm{HEL}} \rho_{0} C_{l} .
$$

Динамический предел текучести $Y_{0}$ гафния определялся с учетом (1) по формуле

$$
Y_{0}=\frac{3}{2} \sigma_{\mathrm{HEL}}\left(1-\left(\frac{C_{0}}{C_{l}}\right)^{2}\right) .
$$

Для расчета значений откольной прочности использовались значения $U_{1}, U_{\min }, U_{2}, \Delta t, U^{\prime}$, обозначенные на профилях $U(t)$ (рис. 3). Откольная прочность гафния рассчитывалась в акустическом приближении. Откольная прочность для упругого материала $\sigma_{\min }$ определя-
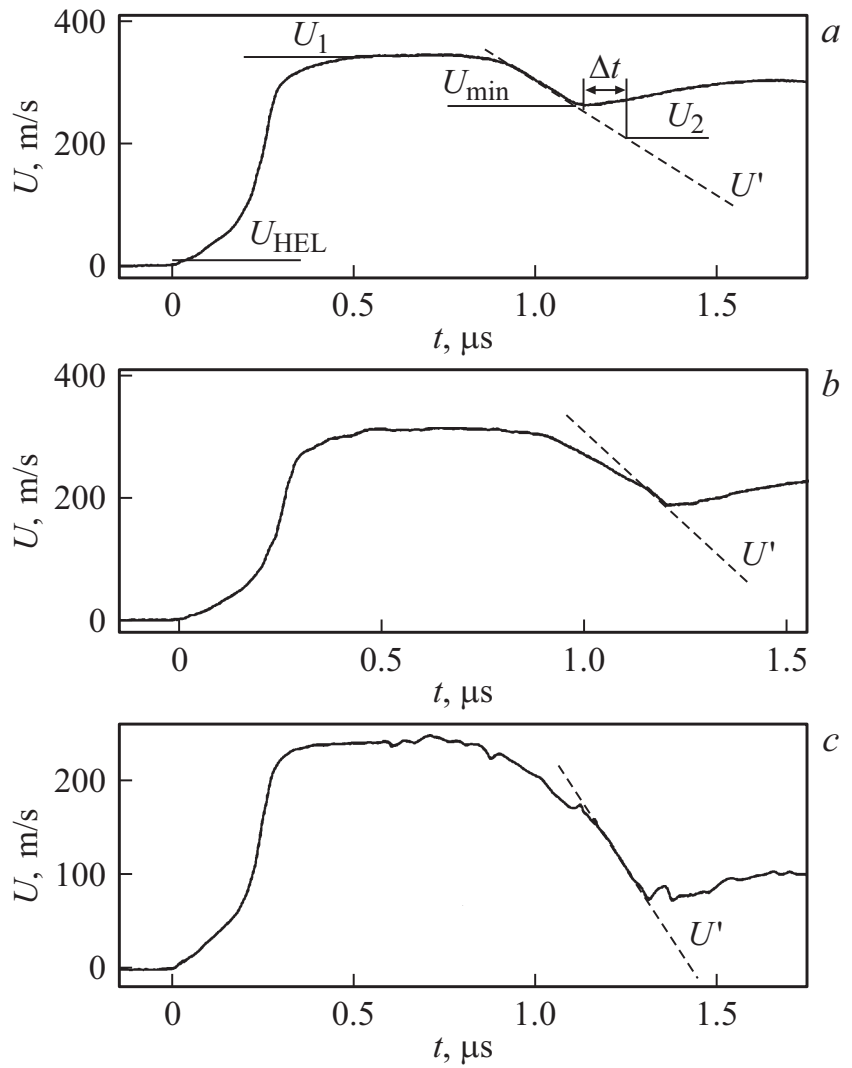

Рис. 3. Профили скорости $U(t)$ тыльной поверхности образцов гафния, контактирующей с воздухом $(a)$, полиметилметакрилатом $(b)$, фтористым литием $(\mathrm{LiF})(c)$. $U_{\mathrm{HEL}}-$ амплитуда скорости $U$, обусловленная динамическим пределом упругости; $U_{1}-$ максимальное значение $U ; U_{\min }-$ минимальное значение $U ; U_{2}$ - скорректированное в соответствии с формулой (5) значение $U_{\min } ; \Delta t-$ разница времен прохождения откольного импульса через откольную пластину, вычисляемая по формуле (6); $U^{\prime}$ - производная по времени скорости $U$ проходящей волны разгрузки в момент выхода откольного импульса на тыльную поверхность образца. 
Таблица 2. Свойства материала окон и откольная прочность гафния

\begin{tabular}{c|l|c|c|c|c}
\hline $\begin{array}{c}\text { Материал } \\
\text { окна }\end{array}$ & $\begin{array}{c}\rho_{0 w}, \\
\mathrm{~g} / \mathrm{cm}^{3}\end{array}$ & $\begin{array}{c}C_{0 w}, \\
\mathrm{~km} / \mathrm{s}\end{array}$ & $\begin{array}{c}\sigma_{\min }, \\
\mathrm{GPa}\end{array}$ & $\begin{array}{c}U^{\prime}, \\
10^{6} \mathrm{~m} / \mathrm{s}^{2}\end{array}$ & $\begin{array}{c}\sigma, \\
\mathrm{GPa}\end{array}$ \\
\hline Воздух & 0 & 0 & $-1.56(3)$ & $-350(10)$ & $-2.5(2)$ \\
PMMA & 1.186 & 2.23 & $-1.67(4)$ & $-610(15)$ & $-3.2(2)$ \\
LiF & 2.64 & 5.14 & $-1.03(4)$ & $-613(15)$ & $-2.9(2)$
\end{tabular}

лась по обычной формуле

$$
\sigma_{\min }=-\frac{\left(U_{1}-U_{\min }\right)}{2} \rho_{0} C_{0}+\frac{\left(U_{1}+U_{\min }\right)}{2} \rho_{0 w} C_{0 w},
$$

где $\rho_{0 w}, C_{0 w}$ - плотность и объемная скорость звука материала окна при атмосферном давлении и комнатной температуре.

Как известно, расчет откольной прочности $\sigma$ для упругопластического материала требует коррекции соотношения (3) (см. работы [5,6] и ссылки в них). Откольная прочность гафния с учетом поправки [5] рассчитывалась по формуле

$$
\sigma=-\frac{\left(U_{1}-U_{2}\right)}{2} \rho_{0} C_{0}+\frac{\left(U_{1}+U_{2}\right)}{2} \rho_{0 w} C_{0 w},
$$

где величина $U_{2}$ вычисляется как

$$
U_{2}=U_{\min }+\Delta t U^{\prime}
$$

В (5) $U^{\prime}$ - производная по времени профиля $U(t)$ в проходящей волне разгрузки в момент выхода откольного импульса на тыльную поверхность образца, $\Delta t$ - разница времен прохождения откольного импульса через откольную пластину толщиной $h$ с объемной $C_{0}$ и упругой $C_{l}$ скоростями звука,

$$
\Delta t=\frac{h}{C_{0}}-\frac{h}{C_{l}} .
$$

Используемые в формулах (3), (4) значения $\rho_{0 w}$, $C_{0 w}$ представлены в табл. 2. Значения $\rho_{0 w}$ и $C_{0 w}$, $C_{l w}$ для полиметилметакрилата взяты из работы [7]. Значение $C_{0 w}$ для фтористого лития рассчитывалось как $C_{0}=\left(K_{0 w} / \rho_{0 w}\right)^{1 / 2}$, где адиабатический модуль объемного сжатия $K_{0 w}$ и плотность $\rho_{0 w}$ фтористого лития при нормальных условиях взяты из работы [8]. В табл. 2 приведены ускорения тыльной поверхности образца $U^{\prime}$, а также значения откольной прочности $\sigma_{\min }$ и $\sigma$.

Значения $\sigma_{\mathrm{HEL}}$ и $Y_{0}$, рассчитанные по формулам (1) и $(2)$, составили $\sigma_{\mathrm{HEL}}=0.27(5) \mathrm{GPa}, Y_{0}=0.17(5) \mathrm{GPa}$, где в качестве погрешности приведены максимальные отклонения от среднего по четырем экспериментам. Отметим, что предел текучести иодированного гафния составляет величину $0.18-0.31 \mathrm{GPa}$ [9]. Таким образом, динамический предел текучести гафния ГФИ-1 практически совпадает с величиной, определенной в статических условиях.
Как видно на рис. 3, фаза сжатия содержит плавно нарастающий участок. Этот факт можно объяснить увеличением предела текучести по мере роста деформации. Следовательно, гафний можно охарактеризовать как упругопластический материал с упрочнением.

Откольная прочность $\sigma_{\min }$ по (3) для каждой серии приведена в табл. 2. Среднее арифметическое для $\sigma_{\min }$ в экспериментах с различными окнами составляет $\sigma_{\min }=-1.4(3) \mathrm{GPa}$, где в качестве погрешности приняты максимальные отклонения от среднего. Упругопластическая поправка (4) существенно увеличивает расчетное значение откольной прочности $\sigma$ (табл. 2). Среднее арифметическое для $\sigma$ в экспериментах с различными окнами составляет $\sigma=-2.9$ (3) $\mathrm{GPa}$, где, как и выше, в качестве погрешности приняты максимальные отклонения от среднего. Отметим, что предел прочности материала пластин из иодированного гафния в статических условиях составляет величину $0.38-0.53 \mathrm{GPa}$ [9]. Таким образом, откольная прочность гафния $\sigma$ в 5-7 раз превышает предел прочности гафния, определенный в статических условиях.

Обсудим различия значений $\sigma_{\min }$ и $\sigma$ в экспериментах с разными окнами. Для воздушного окна это различие (увеличение) составляет $\sim 70 \%$, для окна из полиметилметакрилата увеличение составляет $\sim 90 \%$, а для окна из фтористого лития указанное увеличение достигает $\sim 300 \%$. Причина этого факта главным образом заключается в том, что профиль $U(t)$ в области проходящей волны разгрузки гафния существенно изменяет свою крутизну. Поскольку в экспериментах с различными окнами момент выхода откольного импульса приходится на разные участки $U(t)$, ускорение $U^{\prime}$ в этих экспериментах имеет существенно разные значнеия. Так, например, для окна из фтористого лития величина $U^{\prime}$ почти вдвое больше, чем для воздушного окна (табл. 2). Очевидно, что подобная ситуация будет возникать всегда, когда профиль проходящей волны разгрузки существенно изменяется в области выхода откольного импульса. В таких случаях необходимо уточнять профиль $U(t)$ проходящей волны разгрузки, например используя окна из различных материалов, как это сделано в настоящей работе.

Таким образом, в работе представлены результаты одномерных ударно-волновых экспериментов по регистрации скорости тыльной поверхности пластинчатых образцов гафния марки ГФИ-1 в диапазоне давлений до $7 \mathrm{GPa}$. При этом использовалась методика составных мишеней образец-прозрачное окно. Материалом прозрачного окна служили воздух, полиметилметакрилат и фтористый литий. Анализ полученной информации позволил сделать следующие выводы. Гафний можно охарактеризовать как упругопластический материал с упрочнением. Динамический предел упругости гафния ГФИ-1 равен $\sigma_{\mathrm{HEL}}=0.27(5) \mathrm{GPa}$. Динамический предел текучести этого металла равен $Y_{0}=0.17(5) \mathrm{GPa}$ и практически совпадает с величиной, определенной в статических условиях. Откольная прочность гафния составляет 
$\sigma=-2.9(3) \mathrm{GPa}$ и превышает предел прочности гафния, определенный в статических условиях в 5-7 раз.

Работа выполнена при поддержке Госкорпорации „Росатом“ с использованием оборудования УНУ „Экспериментальный взрывной стенд“ и АЦКП ИПХФ РАН.

\section{Список литературы}

[1] Hazell P.J., Appleby-Thomas G.J., Wielewski E., Escobedo J.P. // Phil. Trans. Roy. Soc. A. 2014. V. 372. P. 20130204.

[2] Казаков Д.Н., Козелков О.Е., Майорова А.С., Малюгина С.Н., Мокрушин С.С., Павленко А.В. // Механика твердого тела. 2014. № 6. С. 68-77.

[3] Gschneidner K.A., Jr. // Solid State Phys. 1964. V. 16. P. 275426.

[4] Barker L.M., Hollenbach R.E. // J. Appl. Phys. 1972. V. 43. P. 4669-4675.

[5] Романченко В.И., Степанов Г.В. // ПМТФ. 1980. № 4. C 141-147.

[6] Канель Г.И. // ПМТФ. 2001. Т. 42. № 2. С. 194-198.

[7] Carter W.J., Marsh S.P. Hugoniot equation of state of polymers.Los Alamos National Laboratory Report N LA13006-MS.Los Alamos, New Mexico,1995. 26 p.

[8] Dong H., Dorfman S.M., Holl C.M., Meng Y., Prakapenka V.B., He D., Duffy T.S. // High Press. Res. 2014. V. 34. P. 39-48.

[9] Коцарь М.Л., Лавриков С.А., Лапидус А.О., Штуца М.Г., Александров А.В., Ахтонов С.Г., Антипов В.В., Бекмансуров Р.Ф., Кулешов С.Ю., Негодин Д.А. // Вопр. атом. науки и техники. 2014. № 2(90). С. 78-84. 